\title{
IN MEMORIAM*
}

\section{J osé Gómez de León Cruces \\ $1946-2000$}

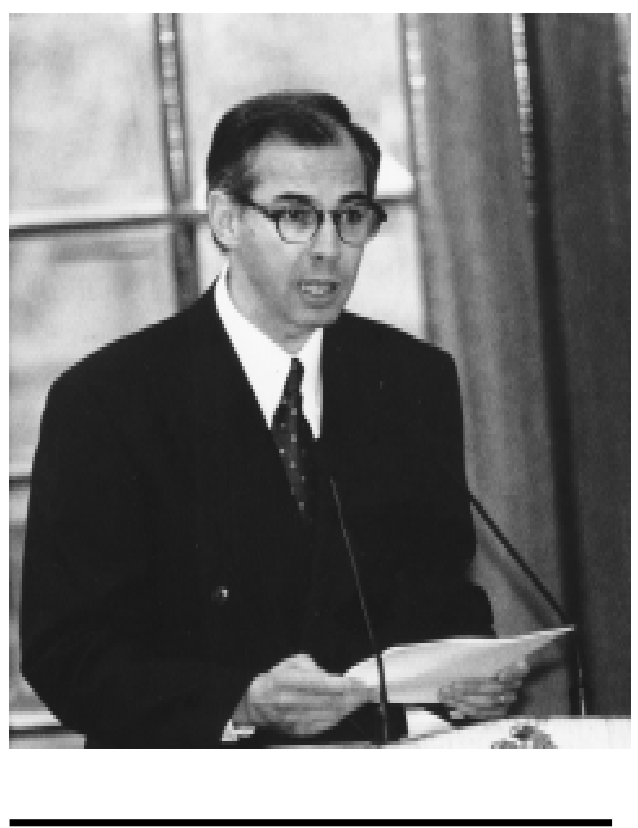

también forma parte de la vida", y nos insta, mediante prescripciones diversas, a aceptarla e incluso hasta festejarla de buena gana en un día siempre especial, casi para seguir viviendo.

Morabito dice que "un vivo sin muertos, sin estirpe, un vivo a secas, no sobrevive". Por ello, nos invita a celebrar a nuestros difuntos, a cantar con ellos, a platicarles cuánto los extrañamos. En esta ocasión, deseamos rendir un sincero y merecido homenaje póstumo, por su legado y calidad humana, a nuestro muy querido y entrañable amigo, el doctor José Gómez de León, quien falleció prematuramente, a los 53 años de edad, el pasado martes 25 de abril en la ciudad de México.
Pepe, como cariñosamente le llamábamos, era una persona llena de virtudes, a quien de manera genuina le importaba la gente. Era un hombre inteligente, sensible, imprescindible y dignamente soberano; de espíritu generoso y miras nobles, que sabía darse y entregarse; una persona siempre bondadosa y buena. Su transcurrir por la vida se expresó en un rico mosaico de diversas y múltiples facetas: se desempeñó como un padre cariñoso y tierno; un esposo amoroso; un amigo incomparablemente cercano y solidario; un excelente académico y profesional, un funcionario honesto y ejemplar; y un jefe amable, respetuoso y siempre exigente.

Vivir era un gozo para él. Amaba la vida con ardor y amaba a su prójimo. Vivió siempre comprometido con su tiempo y con sus circunstancias, convencido de la necesidad de crear una sociedad mejor, más justa. Sus actos construyeron una vida auténtica, inmensa y exigente, que con el paso de los años se fue enriqueciendo y ensanchando, creciendo siempre en vivencias y experiencias, en bondad y sencillez.

Pepe era una persona especial que irradiaba una luz que nos atraía hacia él. Cuando buscábamos el apoyo

\footnotetext{
* Palabras pronunciadas por el doctor Rodolfo Tuirán, Secretario General del Consejo Nacional de Población, en memoria del doctor José Gómez de León Cruces durante la ceremonia inaugural del Taller Internacional "Dinámica de la población indígena de México", Casa Chata, Tlalpan, 16 de mayo de 2000.
} 
del amigo lo encontrábamos pleno, sin ambajes, siempre dispuesto y solidario; cuando las preocupaciones de la vida cotidiana nos asaltaban, siempre supo ofrecernos, con generosidad, las palabras de aliento que necesitábamos; cuando le pedíamos un consejo respondía con comprensión y magnanimidad.

Pepe tenía su propio territorio íntimo, con fronteras selectivamente permeables; su mundo siempre era enriquecido y estimulado por innumerables intereses, pasatiempos y aficiones personales: amaba la música y la lectura; le encantaban la fotografía y la cocina; siempre se mostraba interesado en las diversas manifestaciones de la cultura; le apasionaba viajar y explorar los mundos en los que incursionaba; era un profundo conocedor de la cultura maya; y solía curiosear en las fronteras del conocimiento por vocación y adentrarse en la ciencia por placer.

Pepe era un hombre habitado por sólidos valores. Vivían en él y le daban aliento la libertad, la solidaridad, la pasión por la vida, la confianza y la honradez. Desde su interior, todos estos valores se asomaban permanentemente al mundo a través de sus prácticas y actos cotidianos. Con toda su experiencia a cuestas, siempre logró mantener viva su capacidad de confiar y de no perder la esperanza, fundado en criterios plurales, estrictos, generosos e informados.

Pepe fue siempre joven. Estaba lleno de preguntas que no temía formular y con suma frecuencia intentaba responder. Su mente estaba colmada de saberes sólidamente construidos y, al mismo tiempo, en constante expansión, empeñado en empujar las fronteras de sí mismo, extendiendo en calidad, profundidad y amplitud, sus propios horizontes.

Pepe murió en la cúspide de su impulsos creadores. Se fue cuando todavía tenía tanto que darnos y cuando la vida tenía tanto que ofrecerle. Partió cuando asomaban, maduros, los valiosos frutos de su sólida formación profesional y académica, cuando tenía un tesoro que compartir, producto de muchos años de silenciosa dedicación, estudio y esfuerzo.

Pepe fue maestro de varias generaciones de demógrafos y autor de una amplia y vasta producción científica, cuyo contenido nos hará recordar siempre su nombre y su memoria. Sus aportaciones no sólo se circunscriben a la experiencia de México, sino que muchas de ellas, reconocidas internacionalmente, son generales a toda la disciplina de la demografía. Sus investigaciones reflejan la constancia y continuidad de su trabajo, siempre comprometido con una posición éticosustantiva. Su obra es una referencia invaluable que estoy seguro permanecerá por muchos años $y$, en cierta forma, desafiará al tiempo. Lo hará no sólo por su in- negable valor y rigor científico, sino también porque a través de ella se empeñó en actualizar el pasado, exploró con agudeza el presente y desplegó esfuerzos de imaginación para proyectar el futuro.

La herencia que nos deja está prendida en muchas mentes y en muchos corazones y estoy seguro de que su semilla habrá de crecer y multiplicarse, seguirá viviendo en nosotros y será cada vez más rica. Pero por encima de su obra, Pepe nos deja una lección de vida, de rigor y devoción personal, y un ejemplo de apasionada vocación y entrega.

Con su inteligencia, amistad y don de gente, Pepe nos cautivó y nos permitió acompañarlo a través de un trecho de su vida y de su comprometida trayectoria como funcionario público. Quienes disfrutamos de su amistad y su cercanía, sabíamos de su pasión, de su inquebrantable dedicación, de la constancia y entusiamo con que perseguía su proyecto social; quienes estuvimos a su lado compartimos, por necesidad y admiración, sus apasionadas búsquedas, siempre fascinados por su liderazgo y su capacidad para tomar decisiones y asumir riesgos ponderados.

Fue él quien nos enseñó que la función pública es un verdadero privilegio, que debe ser dignificada de manera permanente mediante nuestro discurso y nuestras acciones y ejercida siempre con honradez. También fue él quien predicó con el ejemplo y desempeñó sus responsabilidades amparado en un cuerpo de principios éticos inviolables.

Pepe era un jefe gentil, afable y educado. Siempre tenía tiempo para quien se lo solicitaba. Su liderazgo no se fundaba en un ejercicio autoritario del poder que le concedía su posición jerárquica, sino que se sustentaba en la disposición a escuchar y dar explicaciones. En el espacio laboral sabíamos por qué ocurrían las cosas y siempre encontrábamos espacios para preguntar, intercambiar opiniones y para valorar conjuntamente las opciones.

Pepe era partidario de otorgar la más amplia confianza y libertad a sus colaboradores, de quienes siempre esperaba lo mejor. Colaborar con él significaba asumir y ejercer plenamente esa libertad y aplicarla con convicción y responsabilidad en las facetas más diversas de los proyectos que él, con su liderazgo y sus conocimientos, supo configurar.

Pepe conservó hasta el final una devoción y una actitud inquebrantable hacia todos sus proyectos, siempre pensando en innumerables planes futuros. Estoy seguro que las tareas y actividades a las que dedicó la última parte de su vida serán continuados después de su muerte, lo cual confirma que, para personas como Pepe, siempre hay un porvenir que se sitúa más allá de 
la muerte y que transforma a este evento casi en un accidente de la vida, que desafortunadamente sigue su curso sin él.

Cada persona se acerca a la muerte de una manera individual y única. Pepe siempre fue fiel a su espejo diario: fue al encuentro de la muerte con entereza, con una gran fortaleza interna y dotado de una singular dignidad. La muerte de Pepe nos ha sacudido en lo más profundo. Su fallecimiento reafirma en mí un hecho obvio, pero no por ello menos trascendental: la vida es pasajera y es apenas un suspiro. Ello no deja de infundirme temor, pero en cierta forma también constituye un alivio y un consuelo.

Muchas experiencias que desencadenan en cada uno de nosotros miedo, vergüenza o rubor parecen tan pequeñas, accesorias, triviales y ciertamente insignificantes frente al carácter definitivo de la muerte. La conciencia de esta temporalidad debe obligarnos a subrayar en nuestra vida cotidiana la enorme importancia del amor al prójimo y debe servirnos para vivir a plenitud y con compromiso nuestra vida "aquí y ahora". De este modo, como solía repetirme Pepe en sus últimos días, la conciencia de la finitud de la vida cambia la perspectiva y nos ayuda a vivir la vida de una manera más plena.

Si la muerte es inevitable en nosotros y en los que nos rodean, aprendamos, como decía Pepe, a vivir más plenamente la vida y a enfrentar la muerte. Si apreciamos la vida seamos capaces de amar al prójimo y de brindar a nuestros vivos el reconocimiento que merecen. Si aceptamos la muerte con serenidad, celebremos a nuestros muertos y honremos su memoria.
El duelo, siempre doloroso, es una reacción necesaria y perfectamente natural ante la muerte de un ser querido. El duelo nos ayuda anímicamente a aceptar y soportar la pérdida, a despedirnos interiormente de nuestro ser querido, y a proseguir nuestra vida sin su presencia. Sólo con la aceptación del carácter definitivo de la pérdida puede quien lleva luto aplicar de lleno su energía a honrar la memoria del ser querido y a volcar su amor por el prójimo.

Les invito a mirar en retrospectiva la vida de nuestro querido y entrañable amigo; hablemos de Pepe y celebremos su vida; tomemos el tiempo que sea necesario para comprender que está muerto y dejemos que la tristeza nos invada y suba como una marea. Pepe ya no está en este mundo, pero su recuerdo habrá de contribuir a fortalecer nuestra comunión con él y con todos los que le sobrevivimos.

Su espíritu nos acompañará por siempre. Tengo la certeza, como dice Villaurrutia, que "el tiempo cierto prolongará nuestro abrazo y será posible, acaso, vivir después de haber muerto". Una de las experiencias más hermosas de mi vida es haber coincidido en tiempo y espacio y compartido tantas cosas con él. Para mí y para muchos de nosotros, su legado siempre será un recordatorio de lo que el ser humano puede alcanzar cuando imprime pasión, entrega y compromiso por una causa. Suscribo las palabras de Martin Luther King, quien solía decir que "Si un hombre no ha descubierto algo por lo que moriría, no está capacitado para vivir". Pepe sabía por qué morir y estaba ampliamente capacitado para vivir. Lamento profundamente su fallecimiento y ruego por el descanso eterno de su alma. 